\title{
La imputación objetiva en el delito de comisión por omisión en la práctica médica ecuatoriana
}

The objective imputation in the crime of commission omission in the Ecuadorian medical practice

\author{
Jaime Arturo Moreno-Martínez \\ jaime.moreno.47@est.ucacue.edu.ec \\ Universidad Católica de Cuenca, Cuenca \\ Ecuador \\ https://orcid.org/0000-0001-8836-3524 \\ María Auxiliadora Santacruz-Vélez \\ maria.santacruz@ucacue.edu.ec \\ Universidad Católica de Cuenca, Cuenca \\ Ecuador \\ https://orcid.org/0000-0001-9617-7289 \\ María Paola Aguilar-Rodas \\ maria.aguilar@ucacue.edu.ec \\ Universidad Católica de Cuenca, Cuenca \\ Ecuador \\ https://orcid.org/0000-0003-2689-392X \\ Juan Carlos Álvarez-Pacheco \\ jalvarezp@ucacue.edu.ec \\ Universidad Católica de Cuenca, Cuenca \\ Ecuador \\ https://orcid.org/0000-0002-7019-9129
}

Recepción: 15 de septiembre 2021

Revisado: 25 octubre 2021

Aprobación: 15 de noviembre 2021

Publicación: 01 de diciembre 2021 


\title{
RESUMEN
}

En la sociedad ecuatoriana, a partir de la vigencia del Código Orgánico Integral Penal del año 2014, se creó una cultura de reclamo hacia muchos galenos, contra quienes se acciona principalmente por la vía penal, por lo que es necesario para la realización de la justicia (como fin), poder delimitar de manera objetiva la responsabilidad (imputación objetiva) concretando el análisis de lo anotado al campo de la omisión de un deber específico, por alejar la conducta debida de la norma imperativa. Ante lo anotado, es fundamental realizar un examen de responsabilidad jurídico penal de la conducta del profesional médico, a través de la imputación objetiva para atribuir la responsabilidad por la conducta omisiva ante la concreción de un resultado que genere daño en un bien jurídico. Se requiere la certeza de que la conducta será investigada con objetividad, permitiendo que el ejercicio de la actividad profesional se desempeñe con confianza.

Descriptores: Derecho penal; derecho público; derecho constitucional. (Palabras tomadas del Tesauro UNESCO).

\begin{abstract}
In Ecuadorian society, from the effective date of the Comprehensive Organic Criminal Code of 2014, a culture of complaint was created towards many doctors, against whom it is mainly acted on by criminal means, which is why it is necessary for the realization of justice (as an end), to be able to objectively delimit the responsibility (objective imputation) specifying the analysis of what is noted in the field of the omission of a specific duty, for distancing the due conduct from the imperative norm. Given the above, it is essential to carry out an examination of criminal legal responsibility of the conduct of the medical professional, through the objective imputation to attribute responsibility for the omissionate conduct before the realization of a result that generates damage to a legal asset. The certainty is required that the conduct will be investigated objectively, allowing the exercise of professional activity to be carried out with confidence.
\end{abstract}

Descriptors: Criminal law; public law; constitutional law. (Words taken from the UNESCO Thesaurus). 


\section{INTRODUCCIÓN}

El primer principio y último fin de cualquier actividad debe ser el ser humano en ejercicio de su intrínseca dignidad, cuidándolo como explica el imperativo Kantiano: "como un fin en sí mismo, al no podérsele tratar como un mero objeto o instrumento" (Rodríguez, 2020). Criterio reconocido y aceptado de manera amplia en occidente. Para ejercer la dignidad y materializar los derechos, los seres humanos requieren de libertad, de esa facultad natural de actuar o no y de ser responsables por los actos. Para disfrutar de aquella libertad se requiere de autonomía, para poder bosquejar un plan de vida, es decir al libre desarrollo de la personalidad, cuyo cimiento es la salud por lo que se debe recordar que la salud como lo define la Organización Mundial de la Salud en el año 1946, es "El estado de completo bienestar físico, mental y social y no solamente la ausencia de afecciones o enfermedades" (Organización Mundial de la Salud, 2021).

Con los presupuestos expuestos poseen pertinencia para el funcionamiento de la sociedad el derecho punitivo y el médico. Áreas de las más fructíferas en cuanto a su evolución, siendo necesarias y de interés para toda la sociedad al incidir de manera determinante sobre bienes jurídicos del más alto valor, como la libertad, la salud, la vida, la autonomía y la integridad corporal, por lo que se demanda a los profesionales médicos más que a otros de diversos ámbitos del conocimiento. A los profesionales sanitarios el derecho los ha acompañado de manera cercana y varios se han encontrado dentro del análisis jurídico para saber si su conducta activa u omisiva ha creado un riesgo no permitido o incrementado uno permitido, debiendo existir los supuestos señalados para imputarlo objetivamente (Domínguez, 2007).

La teoría de la imputación objetiva es fundamental a la luz del derecho penal actual, para poder de manera seria y justa atribuir la conducta de un resultado producido por la acción u omisión de un galeno, siendo esta última la que se estudiará puesto que no es un simple no hacer, sino el no realizar la acción esperada frente al deber jurídico (Alcocer, 2015). La relevancia de la imputación objetiva en la práctica médica, debe ser abordada desde la dogmática para resolver de manera posterior la conducta penalmente relevante. 
Por otro lado, él maestro Marco Antonio Terragni señala lo siguiente acerca de la imputación del resultado en la actividad sanitaria - médica: "La compleja organización social de nuestros días determina la necesidad de distribuir las responsabilidades derivadas de un hecho penal, de manera tal que la imputación objetiva se formule exclusivamente contra quien hubiese defraudado las expectativas que corresponden a su rol" (Terragni, 2003, p. 45).

\section{MÉTODO}

Se trabajó con una investigación de tipo descriptiva documental con diseño bibliográfico, apoyada en el método analítico, teniendo como base a los aportes doctrinarios, jurisprudenciales y la legislación vigente ecuatoriana, así como los aportes más importantes y pertinentes que reposan en libros, artículos, revistas, entre otros tanto físicos como electrónicos, los cuales fueron analizados con apoyo de la técnica de análisis jurídica documental.

\section{RESULTADOS}

Se presentan los resultados de la investigación, en forma de análisis temático, del siguiente modo:

\section{Contexto y realidad normativa y social de la responsabilidad penal del profesional médico en el Ecuador y aproximación a la Teoría General del Delito}

Con el avance en la lectura del presente artículo se clarificará lo que se debe comprender al hablar de imputación objetiva y en que consiste el delito de comisión por omisión, corresponde por ahora y de manera inicial presentar una aproximación al contexto jurídico y social ecuatoriano en materia de responsabilidad médica, tratando en el actual documento los deberes en la práctica médica y el delito culposo sentando en el artículo 146 del (Código Orgánico Integral Penal, 2014), para profundizar en la posición de garante del profesional sanitario - médico y sobre todo con el cómo se debe, a la luz del desarrollo de la dogmática penal atribuir o imputar un resultado. 
Ha existido en el siglo anterior y en el que transcurre, la posibilidad de accionar en contra de un facultativo médico, más era impensable hasta hace poco tiempo un accionar contra ellos, ya que ocupan un sitial en lo más alto de la sociedad, dado su alto grado de formación y su constante esfuerzo en el ámbito humano y económico. Dado el desarrollo constante de la ciencia y de la tecnología deben mantenerse actualizados, calzando en aquella noble actividad y en todas las áreas del conocimiento el claro pensamiento del abogado Eduardo J. Coutere, autor del Decálogo del abogado, que en el primer numeral del texto menciona: "Estudia. El derecho se transforma constantemente. Si no sigues sus pasos, serás cada día un poco menos abogado" (Couture, 2014, p. 11).

Con la expedición de la nueva Carta Magna ecuatoriana en el año 2008, se incorporaron dos artículos novedosos, el primero es el artículo número 54, estableciendo la responsabilidad por mala práctica profesional, con el siguiente texto: “(...) Las personas serán responsables por la mala práctica en el ejercicio de su profesión, arte u oficio, en especial aquella que ponga en riesgo la integridad o la vida de las personas" (Constitución del Ecuador, 2008).

Indicando que quienes pueden -en el desarrollo de su actividad- colocar en riesgo con mayor facilidad que otros profesionales la integridad o la vida de las personas, son los profesionales de la salud. Este primer elemento va creando y de manera adecuada una cultura de pares en la relación médico paciente, iniciando con el fin de una población que presentaba una especie de temor reverencial. Lo que se ha anotado de manera precedente, no debe confundirse con algún tipo de falta de admiración o respeto para con los médicos, muy al contrario, puesto que provengo de líneas familiares médicas que se mantienen por generaciones

Se trata en la norma mencionada, es decir con rango constitucional a la actividad profesional y su responsabilidad, colocando deberes para los profesionales de la salud como el que se encuentra en el artículo 362 de la norma citada. “...garantizarán el consentimiento informado, el acceso a la información y la confidencialidad de la información de los pacientes...”. (Constitución del Ecuador, 2008, art. 362, pg. 111). Reconociendo en el texto derechos de los pacientes, consecuentemente obligaciones 
para los profesionales de la red pública y privada de salud, que no son discrecionales o facultativos, por lo tanto, son imperativos.

En el año 2014, mientras se realizaba el debate legislativo y social por el nuevo y hoy vigente Código Orgánico Integral Penal se presentaban por parte de la prensa, colectivos y algunos asambleístas, innumerables casos de pseudo malas prácticas médicas, evidenciadas desde el testimonio de las víctimas directas y sus familiares, con imágenes crudas pero reales, que concentraron el debate nacional y que políticamente permitió acorralar gran parte del debate que merecían otros puntos en aquella materia.

La conmoción social inició, la vindicta se generalizó y la clase médica que goza de muy buena organización y recursos salió al frente acompañada de profesionales del derecho para poner verdades en las mentiras y colocar razón al dolor. Dentro de los temas que se corrigieron por ser mal informados y no corresponder a la verdad, se aclaró que muchos de los casos presentados evidenciaban en ocasiones lesiones permanentes y en otros casos muerte, que no se realizaron en casas de salud autorizadas, ni por profesionales acreditados, por lo tanto, no se pudo tratar de malas prácticas en el ejercicio profesional de la salud o de deficiente prestación en los servicios sanitarios.

Si cabe la expresión, el daño fue hecho y la regulación avanzó gozando del equilibrio y por ello un tratamiento distinto para el caso de lesiones y homicidio culposo por mala práctica profesional. Las lesiones se encuentran tipificadas en el artículo número 152 del Código Orgánico Integral Penal, que menciona las reglas para aplicar las sanciones, pero aclara lo siguiente: “...No serán punibles las lesiones derivadas de acciones terapéuticas ejecutadas por profesionales de la salud en cumplimiento del principio de necesidad que precautele la salud del paciente" (COIP, 2018, art. 152, pg. 72).

El artículo al cual se hace referencia en líneas anteriores alcanzó un acuerdo de manera rápida comparado con el artículo 146, que poseyó múltiples y profundas deliberaciones. Debe tenerse de manera clara lo siguiente que me permito acentuar del artículo anteriormente citado: "1. La mera producción del resultado no configura 
infracción al deber objetivo de cuidado...4. Se analizará en cada caso la diligencia, el grado de formación profesional, las condiciones objetivas, la previsibilidad y evitabilidad del hecho" (COIP, 2018, pg. 323)

La legitimidad en la actuación del profesional de la salud al incidir en los bienes jurídicos del paciente se alcanza con el consentimiento informado y realizado en la forma que dispone la normativa ecuatoriana constante en varios instrumentos, particularmente en el Acuerdo Ministerial número 5316, publicado en el Registro Oficial número 510, de fecha 22 de febrero del año 2016 (Ministerio de Salud Pública del Ecuador, 2016).

La clase médica no quedó satisfecha con la redacción del tipo calificado de homicidio culposo por mala práctica profesional, en cuanto toda intervención sanitaria es peligrosa, el término innecesario en medicina es ambiguo o bajo que presupuestos, un tratamiento es ilegitimo, con lo señalado quedaban vulnerables y sin certezas para el desempeño de su rol, ya que existe la duda acerca de que podría comprender el juzgador. Lo anotado llevó a sendas manifestaciones públicas y otras acciones que culminaron con una resolución de la Corte Nacional de Justicia, que en su parte correspondiente señala: “... que se configura por la inobservancia del deber objetivo de cuidado por la concurrencia de acciones innecesarias, peligrosas e ilegítimas" (COIP, 2018, art. 3, pg. 325). Es decir, para que proceda el delito calificado deben encontrarse presente las tres condiciones expuestas.

\section{Teoría General del Delito}

Los lectores con conocimientos acerca de la Teoría General del Delito podrán encontrar muy ligero el tratamiento que se presenta, sin embargo, podrán recordar los cuatro elementos de la misma, más para quienes no lo son les permitirá formarse una idea inicial con el fin de comprender el trabajo posterior en este artículo y ubicar en la norma penal vigente los cuatro elementos del delito expuestos (Muñoz, 2018). Una teoría es lo que permite explicar algo o lo que ayuda a comprender un conjunto de pensamientos aceptados de manera general. 
Lo expresado en el derecho penal se denomina teoría general del delito, siendo en palabras del tratadista Terragni (2012): "Un sistema que mediante la determinación de categorías establece cuáles son los presupuestos jurídico-penales, de carácter general, que deben concurrir para establecer la existencia de un delito; es decir, permite resolver cuándo un hecho es calificable como delito" (p. 57). De manera sencilla, el doctrinario (Muñoz, 2018), enseña lo que es un delito al anotar que es toda conducta que el legislador sanciona con una pena. Con los conceptos expuestos se torna fácil comprender que la teoría general del delito es un conjunto de elementos comunes, que se relacionan y que deben cumplirse uno por uno: a) conducta, b) típica, c) antijurídica y d) culpable. La ausencia de cualquiera de estos cuatro elementos extingue el delito.

El Código Orgánico Integral Penal indica en su artículo 18, que la infracción penal: "Es la conducta, típica, antijurídica y culpable cuya sanción se encuentra prevista en este Código" (COIP, 2018, art. 18, pg. 38). Verificados estos cuatro elementos se puede sancionar a determinada persona por haber cometido un delito. Para recordar que significa cada elemento anotado y cuya claridad es fundamental para la comprensión del presente trabajo, se ensayará de manera epidérmica una síntesis introductoria de cada uno.

\section{Conducta}

Para que exista una conducta activa u omisiva se requiere que se dé una coincidencia entre la conciencia y la voluntad, siendo propicio recordar que no todas las conductas interesan al derecho y al tenor del artículo 22 de la norma penal ecuatoriana, son importantes en función de los bienes jurídicos que protejan (son penalmente relevantes las acciones $u$ omisiones que ponen en peligro o producen resultados lesivos, descriptibles y demostrables) (COIP, 2018, art. 22). La acción es fácil comprender, puesto que exterioriza un hacer. El inicio se encuentra en el pensamiento de Hegel: "Por la aplicación del principio lógico de que la negación de la negación es la afirmación: el delito es la negación del derecho y la pena es la negación del delito, o sea, la afirmación del del derecho" (Zaffaroni et al. 2006, p. 401). Existen escenarios 
en los cuales la conducta se entiende inexistente y sus causas de exclusión son: la fuerza física irresistible, estados de inconciencia y el movimiento reflejo.

El primero indica la imposibilidad de moverse de acuerdo a su voluntad, el segundo se produce cuando existe perdida de la posibilidad de reconocer lo que sucede y el tercero cuando el movimiento es autónomo. Por su parte la omisión no es un simple no hacer algo, es el no cumplir con el deber jurídico. Como explica el maestro (Muñoz, 2018): “Acción y omisión no son, por tanto, dos formas ontológicamente distintas (A y B) del comportamiento humano, sino dos subclases independientes ( $A$ y no $A$ ) del comportamiento humano, susceptibles de ser regidas por la voluntad final" (p. 29). O como se plasma: "Omitir es un verbo transitivo. No significa no hacer, sino no hacer algo" (Zaffaroni et al. 2006, p. 403). Debe quedar grabado en la mente del lector por lo cual se insiste en que la conducta puede exteriorizarse a través de una acción o de una omisión.

Es imprescindible apoyar lo ulterior en la dogmática penal, iniciando con las enseñanzas del maestro Francisco Muñoz Conde, como uno de los más claros doctrinarios en la materia, lo cual permite afirmar los conocimientos acerca de la Teoría General del Delito, recordamos en palabras del maestro que: "Toda acción u omisión es delito si infringe el ordenamiento jurídico (antijuridicidad) en la forma prevista por los tipos penales (tipicidad) y puede ser atribuida a su autor (culpabilidad)" (Muñoz, 2018, p. 33).

\section{Tipicidad}

La tipicidad es elemento de estudio más extenso en la teoría del delito y en ella se analizan varias características, siendo de interés para el presente trabajo la imputación objetiva. Debe distinguirse lo típico de la tipicidad, el primer término indica la descripción establecida en la ley y el segundo es el ajuste de la conducta a lo anotado o descrito en la norma penal, su encaje debe ser perfecto. La tipicidad se encuentra definida en el Código Orgánico Integral Penal, en su artículo 25. Indicando lo siguiente (Tipicidad. - Los tipos penales describen los elementos de las conductas penalmente relevantes) (COIP, 2018, art. 25, p. 18). La tipicidad estudia tres elementos: a) la conducta típica, b) los sujetos y c) objeto. 
Conducta típica: El primer elemento se lo debe comprender como la acción u omisión que se enmarca o ajusta a lo que el legislador ha considerado como infracción penal, para mayor comprensión se puede sentar como el delito establecido en la norma penal ecuatoriana. Esta conducta típica posee a su vez dos elementos que la integran, siendo el primero objetivo y el segundo subjetivo.

Por el elemento objetivo se comprenden a las manifestaciones externas, descripciones que deben tener por lo menos un verbo rector y a veces suelen poseer circunstancias complementarias. Por su parte, el elemento subjetivo indica el sentir de lo que en la legislación ecuatoriana vigente puede traducirse al dolo o culpa, descritos en el Código Orgánico Integral Penal en los artículos 26 y 27 en su orden.

Sujetos: El sujeto activo es quien ajusta su conducta a lo descrito en la norma penal, es decir, el infractor penal - delincuente, pudiendo los ciudadanos nacionales 0 extranjeros en el territorio nacional cometer: un delito común cualquier persona y los delitos propios lo comete quien tiene características definidas en cuanto a su rol. El sujeto pasivo es quien sufre o soporta la lesión al bien jurídico. El Estado con todo su poder se enfrenta contra un médico, puesto que toda la maquinaria estatal con su potencia se activa en los delitos de acción pública.

Objeto: El objeto jurídico es lo que se desea proteger y al hablar del objeto material se debe entender y pensar en la persona o cosa sobre la que se ha cometido o va a cometerse el delito.

\section{Antijuridicidad}

Por antijuridicidad se comprende a aquellas conductas activas $u$ omisivas contrarias al derecho. El Código Orgánico Integra Penal lo trata en su artículo 29 al señalar que: "Para que la conducta penalmente relevante sea antijurídica deberá amenazar 0 lesionar, sin justa causa, un bien jurídico protegido" (COIP, 2018, art. 29, pg. 20). La antijuridicidad posee dos capas: que son la formal y el material; siendo la primera de fácil tratamiento, puesto que debe adecuarse al tipo penal, por su parte el segundo analizará el contenido del injusto, es decir, la lesión o puesta en peligro de un bien jurídico protegido. 
Las causas de exclusión de la antijuricidad se encuentran en el artículo 30 de la norma penal ecuatoriana y son: "....estado de necesidad o legítima defensa...orden legítima y expresa de autoridad competente o de un deber legal" (COIP, 2018, art. 30, pg. 20). Cabe anotar que el consentimiento informado es un presupuesto de licitud y elimina la antijuridicidad.

\section{Culpabilidad}

La norma penal ecuatoriana vigente define de manera muy comprensible lo que es la culpabilidad, al señalar que: "Para que una persona sea considerada responsable penalmente deberá ser imputable y actuar con conocimiento de la antijuridicidad de su conducta" (COIP, 2018, art. 34, pg. 21). No todas las personas son imputables si su conducta es típica, más para saber quiénes no lo son se debe analizar la culpabilidad a partir de sus exclusiones, procediendo a revisar la: perturbación mental, el error de tipo y de prohibición.

La perturbación mental implica que la persona no puede darse cuenta, conocer las implicaciones de su conducta, es estos casos cuando es absoluta no merecen prisión, pero sí medidas de seguridad, como lo refiere nuestra norma penal del Ecuador en el artículo 588: "Si la persona investigada o procesada muestra síntomas de trastorno mental, la o el fiscal ordenará su inmediato reconocimiento, para cuyo fin designará a un perito médico psiquiatra, quien presentará su informe en un plazo determinado. De este informe dependerá el inicio de la instrucción, la continuación del proceso o la adopción de medidas de seguridad, según el caso" (COIP, 2018, art. 588, pg. 212). Al analizar la culpabilidad, es fundamental revisar si la conducta fue dada por error, aquel "vicio del consentimiento causado por equivocación de buena fe, que anula el acto jurídico si afecta a lo esencial de él o de su objeto" (Torres-Proaño \& SalazarSánchez, 2016), pudiendo ser de tipo y de prohibición; distinguiéndose estos porque en el primero el sujeto activo, es decir quien comete la infracción penal, desconoce los elementos objetivos del tipo penal, en otras palabras, no sabe qué es un delito lo que se encuentra realizando.

La norma penal vigente en el Ecuador trata lo anotado de la siguiente manera: "Error de tipo. - No existe infracción penal cuando, por error o ignorancia invencibles 
debidamente comprobados, se desconocen uno o varios de los elementos objetivos del tipo penal. Si el error es vencible, la infracción persiste y responde por la modalidad culposa del tipo penal, si aquella existe. El error invencible que recae sobre una circunstancia agravante o sobre un hecho que califique la infracción, impide la apreciación de esta por parte de las juezas y jueces" (COIP, 2018, art. 28.1, p. 19).

En el segundo tipo de error, el de prohibición, el sujeto activo sabe lo que se encuentra realizando, pero considera que su conducta es conforme al derecho, en palabras del maestro (Muñoz, 2018), el autor cree que actúa lícitamente. Se emplearán las enseñanzas del maestro Edgardo Alberto Donna para explicar la diferencia entre el error de prohibición evitable y el error inevitable.

Evitable: "Está claro que existe una menor culpabilidad del autor, ya que no se ha podido motivar de manera correcta por la norma; luego, la pena también debe disminuirse" (Donna, 2013). Inevitable: "No se podrá hacer ningún tipo de reproche al autor por su conducta antijurídica, ya que no se sabe que aquél lo es, con lo cual debe descartarse su culpabilidad" (Donna, 2013).

Causalidad e imputación objetiva: Se vive en una sociedad de peligro, de inseguridad y en la cual el conflicto, es decir, la confrontación de intereses que nos exponen a permanentes riesgos, encontrando diversos motivos y maneras de interactuar. Algunas conductas se adscriben en un segmento muy pequeño que observa las normas jurídicas por el deber ser, y otras, a quienes les gusta coquetear de manera permanente con los límites.

Forzosamente se está obligado, por las necesidades cotidianas u extraordinarias, a coincidir con otros en sociedad en entornos naturales o creados y que, con el permanente desarrollo, la vida se vuelve más vertiginosa. La seguridad es un deseo y una búsqueda constante de los individuos y de la colectividad, a tal punto que la propia (Organización de las Naciones Unidas, 1945), se crea, tal como lo declara su carta fundacional, con el propósito de mantener la paz y la seguridad. Por ello el juego social debe ser controlado y quienes hagan trampa deben ser sancionados, apartados para incorporarse de manera posterior a la convivencia. La atribución de la responsabilidad penal no puede efectuarse de manera arbitraria, por ello es necesario 
imputar la comisión de una infracción penal de manera técnica y a quien en verdad le corresponda.

El tratadista (Guérez- Tricarico, 2012), señala que para imputar objetivamente el resultado no basta con que la conducta sea la causa del resultado producido (relación de causalidad, que se mantiene en un plano meramente naturalístico), sino que es preciso constatar una específica relación normativa entre la acción y el resultado, es decir, que la conducta delautor haya creado un riesgo jurídicamente desaprobado de los que la norma que prohíbe la acusación del resultado típico pretendía evitar y que ese riesgo se haya concretado en el resultado. Lo anotado es coincidente con lo establecido en el artículo 146 del Código Orgánico Integral Penal, que en su numeral primero señala: “...La mera producción del resultado no configura infracción al deber objetivo de cuidado" (COIP, 2018, art. 146, p. 56).

Por ello, se debe analizar cómo imputar el resultado. El análisis a lo largo de la historia ha evolucionado en cuanto a saber lo que existe entre la conducta y el resultado y ese intermedio es la causalidad, es decir, el origen, lo que generó el resultado. La búsqueda para hacer lo correcto, llevó a explorar teorías con el método de las ciencias naturales - individualizadoras, para encontrar la causa y de manera posterior se crearon las teorías valorativas. 


\section{Las teorías individualizadoras}

Teoría de la Equivalencia/Teoría de la Condición: Indica que todas las condiciones son equivalentes, iguales, es decir, todas son semejantes y todo genera el resultado, y en palabras del maestro Claus Roxin (2019) "Debería considerarse causa a cualquier condición del resultado que no pudiera ser suprimida mentalmente sin que el resultado concreto desapareciera (...) causa toda conditio sine qua non, es decir, cualquier condición sin la cual el resultado no se hubiera producido" (p. 85). Es decir, si se elimina una de las condiciones el resultado ya no existiría y es por ello que todas son equivalentes.

Teoría de la adecuación: La segunda es la denominada teoría de la adecuación que de manera sucinta indica cuál sería causal en sentido penal solamente aquella conducta que poseyera una tendencia general para provocar el resultado típico (Roxin, 2019). En otras palabras, es la causa más lógica para haber producido el resultado.

Teoría de la causa próxima o inmediata: El tratadista Señor Doctor Andrés Esteban Jaimes (2021) indica acerca de esta teoría que bastando considerar la causa que ha sido inmediatamente anterior al daño, sin que se requiera remontarse a un grado más distante. Es evidente que estas teorías buscan la externalización de la acción y no son suficientes, puesto que excluyen análisis de realidades de la más profunda trascendencia, como la que reviste la omisión que es la de nuestro interés. Ante ello, aparecen las teorías valorativas: Adecuación social de la conducta e imputación objetiva.

\section{Teorías valorativas:}

Adecuación social de la conducta: Por la adecuación social de la conducta se comprende que es lo que es socialmente correcto, aceptado.

La imputación objetiva: Nace para resolver los problemas de causalidad desde el punto de vista jurídico, ante la incapacidad de las teorías señaladas para satisfacer las interrogantes de mayor complejidad, fue fundamental encontrar alternativas mejores para solucionar los problemas que presenta la causalidad siendo la imputación objetiva la que alcanzó consenso hasta nuestros días. 
Los exponentes de la teoría de la imputación objetiva con mayores credenciales son Claus Roxin y Günter Jakobs, de quienes se resume lo pertinente de sus obras que se titulan de manera idéntica: La imputación objetiva en el Derecho Penal. Para el maestro Claus Roxin, el derecho penal existe para proteger bienes jurídicos y para el maestro Günter Jakobs la razón del derecho penal es la de proteger la vigencia de la norma, porque si la norma es incumplida pierde vigencia.

Guardando las evidentes distancias y basado en las enseñanzas de los maestros se concluye lo siguiente: la ley se crea para proteger bienes jurídicos pero el derecho penal concurre para proteger la vigencia de la norma, ya que solo así, a través de ella se protegen los bienes jurídicos. Ante problemas realmente dificultosos en cuanto a la causalidad encuentran aceptación las teorías valorativas, siendo la primera la de adecuación social de la conducta que dice que hay que mirar lo que socialmente es correcto, lo que socialmente es adecuado y ya en un análisis jurídico de valoración para resolver las interrogantes de la causalidad se acepta y mantiene hasta la fecha con credibilidad la teoría de la imputación objetiva.

La imputación objetiva, como se ha señalado, posee dos visiones potentes: 1.- Claus Roxin: Se debe estudiar si la conducta que generó el resultado creo un riesgo no permitido o incrementó un riesgo permitido. Caso contrario, la conducta es intrascendente jurídicamente, ya que actuó dentro de los riesgos permitidos, poseen también causas en las cuales existiendo imputación objetiva se anula o excluye la misma. Las causas de anulación o exclusión son las siguientes:

La disminución del riesgo: Cuando se crea un riesgo no permitido puesto que busca evitar o disminuir un riesgo mayor. El maestro (Roxin, 2019) enseña: Cuando el autor ha modificado un curso causa de tal manera que disminuye el peligro ya existente para la víctima, o sea cuando mejora la situación del objeto de la acción. 2.- Riesgo socialmente adecuado: Debe analizarse el lugar en el cual se desarrolla una conducta, ya que puede ser necesaria su realización por ser que es socialmente adecuado. No puede prohibirse la provocación de una conducta socialmente normal y generalmente no peligrosa (Roxin, 2019). 3.- Riesgo mínimo o riesgo insignificante: Es tan mínimo que no interesa al derecho penal. Es una conducta 
normal que produce un desenlace no deseado. 4.- Ámbito de protección de la norma: Cuando la norma se encuentra creada para proteger algo distinto al resultado que se suscitó, o en otras palabras y con la autoridad de (Roxin, 2019): La infracción del riesgo permitido ha elevado de antemano claramente el peligro de un desarrollo tal como el que después se produce, pese a lo cual no debe tener lugar una imputación del resultado. 5.- Conducta alternativa conforme a Derecho: Se inobserva la norma, pero a pesar de aquello, si se hubiese observado la mismo igual se produce el resultado. Debe excluirse la imputación cuando la conducta alternativa conforme a derecho hubiera llevado con seguridad al mismo resultado (Roxin, 2019). Günter Jakobs.- Hace suyos los enunciados del sociólogo Niklas Luhmann quien enseñaba que existen tres elementos inseparables: la persona, la sociedad y las normas. Imaginen que los seres humanos conviven en un juego, con reglas claras y que quien las incumple hace trampa a la sociedad, por lo que debe ser separado de este juego para que los observadores del derecho continúen realizando sus actividades con normalidad. Como ejemplo, si se juega monopolio y en el dado se obtienen dos marcas, implica que no se dará un paso o tres y por supuesto no se abstendrá de hacerlo. Solo así es posible la convivencia. Si alguien incumple con su rol abusa a sus iguales.

Jakobs enseña que si una norma no es respetada pierde eficacia y es el derecho el que debe restituirla. (Bernate, 2010), indica que lo relevante es la defraudación de expectativas, expectativas que se derivan de un determinado rol. Günter Jakobs busca que la norma sea fuerte, que sea respetada por todos quienes actúan en sociedad, a fin de que la misma funcione de manera adecuada. Quien observa las normas no desafía al derecho y por lo tanto no lo enfrenta. De manera sencilla se evidenciará lo que debe entenderse por: Prohibición de regreso, principio de confianza e imputación a la víctima.

Prohibición de regreso. - Debe entenderse por la conducta que en el cumplimiento de un rol determinado y son conocimiento de un hecho contrario a la Ley favorece a la comisión del delito, por lo que no debe ser imputado. 2.- Principio de confianza. - Solo opera en relaciones horizontales como, por ejemplo, en un quirófano en el cual 
cada miembro cumple con su rol y debe estar preocupado por el rol / trabajo de los otros. El principio de confianza no opera en relaciones jerárquicas o verticales. 3.Imputación a la víctima. - se requiere que la víctima haya actuado en ejercicio de su libertad con lo que se denomina auto puesta en peligro, volviéndose responsable.

\section{ANÁLIIS JURÍDICO DE LA CONDUCTA OMISIVA}

Complementando a lo ya tratado sobre la conducta omisiva indicamos con la finalidad, de que quede en el lector de manera clara las particularidades de la misma. La omisión es no cumplir con el deber jurídico y aquella conducta omisiva puede ser propia o impropia, está ultima también se denomina como comisión por omisión. La omisión propia posee las siguientes características: es de peligro, lo que quiere decir que no requiere de un resultado, se encuentran en el catálogo de delitos código penal y puede ser cometido por todos los ciudadanos y en su normativa es prohibitiva de realización de determinadas conductas.

A diferencia de lo anotado, la comisión por omisión no incumple normas prohibitivas sino imperativas, necesariamente deben poseer un resultado y no se encuentran catalogadas las diferentes conductas, no pueden incurrir en aquellas infracciones penales todos los ciudadanos, sino solo quienes se encuentren en posición de garante. Las conductas penalmente relevantes para la norma penal ecuatoriana sentada en el artículo 22 del Código Orgánico Integral Penal, son:“... las acciones u omisiones que ponen en peligro o producen resultados lesivos, descriptibles y demostrables" (COIP, 2018, art. 22, pg. 18); e indica la norma anotada en su artículo 23 que existen dos modalidades de conducta: "La conducta punible puede tener como modalidades la acción y la omisión"(COIP, 2018, art. 23, pg. 18). 
Tabla 1.

Acción comparativa.

\begin{tabular}{|l|l|}
\hline ACCIÓN: hacer. & OMISIÓN: no hacer la acción jurídica esperada. \\
\hline OMISIÓN PROPIA & COMISIÓN POR OMISIÓN \\
\hline Es de peligro & Es de resultado \\
\hline Expresamente tipificada & No está tipificada \\
\hline Todas las personas lo pueden cometer & Solo puede cometer el garante. \\
\hline Normas prohibitivas & Normas imperativas \\
\hline
\end{tabular}

Elaboración: Los autores.

La conducta de interés para el presente trabajo de estudio, es la comisión por omisión, la misma que será tratada con mayor profundidad de manera ulterior. La posición de garante posee diversas fuentes, como por ejemplo la ley, el contrato y el deber de controlar una fuente de peligro. Para salvar la duda del lector acerca de cómo debe comprenderse la posición de garante, se presenta el tratamiento que presenta la legislación penal ecuatoriana al señalar en su parte pertinente que: "Se encuentra en posición de garante la persona que tiene una obligación legal o contractual de cuidado o custodia de la vida, salud, libertad e integridad personal del titular del bien jurídico" (COIP, 2018, art. 28, p. 19).

\section{POSICIÓN DE GARATE DEL PROFESIONAL DE LA SALUD}

Se conoce que la omisión impropia o comisión por omisión es un delito de resultado y que se lo debe atribuir a su responsable. La imputación con base a lo revisado es fácil comprender desde las teorías naturalísticas o valorativas cuando se trata de acciones, pero adquiere una inicial complejidad cuando se analiza cómo realizarla en las omisiones.

En este sentido, (Muñoz \& García, 2010), recuerdan que se debe efectuar un análisis de causalidad hipotética, es decir, la posibilidad fáctica que tuvo el sujeto de evitar el resultado. El derecho no exige conductas heroicas a nadie, por lo tanto, tampoco se 
legisla al margen de la racionalidad, por lo que es lógico comprender que a quien se le exige una conducta es porque se encuentra en capacidad de realizarla.

La posición de garante: El delito de comisión por omisión solo puede ser cometido por el garante y esa posición no se crea por generación espontánea, forzosamente requiere que la persona se encuentre por la función que desempeña siendo responsable del bien o de los bienes jurídicos protegidos de un tercero obligándose a evitar un desenlace no deseado. La posición de garante nace de diversas circunstancias como: de la ley, el contrato y la injerencia. Se tomarán los ejemplos inconfundibles a los que los autores mayoritariamente recurren y que también se encuentran en la obra denominada Teoría General del Delito del maestro Francisco Muñoz Conde.

Ejemplos: De la ley: Evoca el autor a una vinculación natural de la cual nace la posición de garante de los padres hacia sus hijos, como son alimentos, protección. Contrato: El que adquiere un salvavidas para proteger a los bañistas. Injerencia: Cuando se crea una fuente de peligro es responsable quien la crea de sus consecuencias. Como quien tiene un perro y lo lleva a pasear sin sus debidas seguridades, como una correa o bozal y al ver a un niño en bicicleta se lanza contra él y lo muerde. Comunidad de peligro: Cuando se ejercen deportes de manera colectiva como es el andinismo. Voluntariado: socorristas, niñeras, médicos. Muñoz (2018) menciona que todas aquellas personas que de forma expresa o tácita asumen la obligación de impedir determinados resultados, obligación que constituye precisamente el objeto de su aceptación (Muñoz, 2018).

El tratadista Francisco (Bernate, 2010), inscribe coincidentemente con Muñoz (2018) a la actividad médica en una asunción voluntaria: "La posición de garante del profesional de la salud se desprende de la asunción voluntaria del tratamiento del paciente, en concreto se inicia con el diagnostico. Mientras no se asuma el tratamiento del paciente, el médico no asume la posición de garante por lo que debe tratarse como cualquier otro ciudadano". Bernate (2010) trae para sí la posición del tratadista Enrique Bacigalupo, quien enseña de manera coincidente que la posición de garante del médico no proviene de la ley ni del acto anterior y, en muchos casos tampoco 
puede tener su fundamento en un contrato, dado que en muchos casos el paciente mayor de edad no podrá prestar su consentimiento válidamente y quienes lo prestan por él carecen de mandato. Será verdaderamente absurdo que cuando el paciente más lo necesita, menor sean las obligaciones del médico.

Cabe señalar que en la legislación ecuatoriana no existe el deber de socorro como en otras legislaciones, su incumplimiento sería una omisión propia lo cual apunto por frecuentes confusiones. En los posibles escenarios de toma de posición de garante por parte de un facultativo médico no existe confusión salvo en la que se da por injerencia, zanjando la duda el tratadista Bernate Ochoa, al enseñar que existe por no controlar adecuadamente una fuente de peligró la medicación.

No se debe olvidar que la relación médico paciente existe por diversas fuentes, entre ellas la conducta voluntaria y el contrato y que en la gran mayoría su obligación es de medios no de resultados, pero que de darse un resultado no deseado que lesiones bienes jurídicos protegidos, no responderá salvo infracciones al deber objetivo de cuidado y de la lex artis ad hoc.

Es conveniente precisar que la legitimidad de un tratamiento, es decir, poseer la autorización del titular de los bienes jurídicos con conciencia y voluntad, no constituye una patente de corso para justificar cualquier resultado. Es preciso recordar que la actividad profesional e insustituible de los médicos en su gran mayoría y casi como regla general no exige un resultado, más si la observancia de la lex artis / deber objetivo de cuidado, por lo que se debe, a través de la imputación objetiva, atribuir si corresponde una necesidad, libre de los juzgamientos paralelos que se crean empleando medios telemáticos principalmente y del populismo penal.

En palabras del maestro Marco Antonio Terragni (2003): "Si el autor ha creado un peligro jurídicamente desaprobado para la producción del resultado. Esto teniendo en Cuenta que las normas jurídicas solo prohíben acciones que aumentan el peligro al que está expuesto un bien jurídicamente protegido" (p. 151). 


\section{CONCLUSIONES}

Se ha podido constatar en el desarrollo del presente trabajo al que se suma la práctica profesional en derecho sanitario del autor, que, si existe en el Ecuador un tratamiento doctrinario acerca del delito de comisión por omisión, pero lamentablemente un tratamiento deficiente, casi inexistente en producción nacional cuando se trata del derecho sanitario que lleva como cualquier área del conocimiento sus particularidades.

Al no haberse desarrollado el tratamiento académico en las facultades de derecho y medicina, como tampoco en la doctrina nacional, se ignora por parte de muchos operadores de justicia y abogados, que por lo general al profesional de la salud no se le puede exigir un resultado, sino la aplicación de medios que observen el deber objetivo de cuidado y la lex artis tanto general como ad - hoc.

El deber objetivo de cuidado es ignorado por la mayoría de los galenos, quienes adecuan su conducta guiados solo por la lex artis y la costumbre en cuanto a la organización de los equipos de trabajo, en relaciones principalmente de tipo vertical u horizontal.

Por ventaja para los profesionales de la salud, el derecho y la justicia, existe la imputación objetiva cuando debe analizarse si ha ocurrido o no un resultado no querido que hiere bienes jurídicos como la vida, la salud o la integridad corporal, sentándose con claridad que la posición de garante es la que obliga a cumplir con un deber jurídico y en su inobservancia a asumir las consecuencias una vez atribuidas las mismas observando el debido proceso.

Concluyendo de manera categórica que en el Ecuador el régimen jurídico penal ecuatoriano establece la posibilidad de atribuir responsabilidad a un médico en el ejercicio de la profesional a través de la imputación objetiva por un delito de comisión por omisión. 


\section{FINANCIAMIENTO}

No monetario.

\section{AGRADECIMIENTO}

A la Universidad Católica de Cuenca; por motivar el desarrollo de la investigación.

\section{REFERENCIAS CONSULTADAS}

Alcocer, W. (2015). Teoría de la imputación objetiva en la jurisprudencia peruana. Desarrollo jurisprudencial a partir del año 2011 [Theory of objective imputation in Peruvian jurisprudence. Jurisprudential development from the year 2011]. $\begin{array}{llll}\text { Derecho } y & \text { cambio social, } & 12(42), & \end{array}$ https://dialnet.unirioja.es/servlet/articulo?codigo=5456411

Bernate, F. (2010). Imputación Objetiva y Responsabilidad Penal Médica [Objective Imputation and Medical Criminal Liability]. (primera). Bógota: Universidad El Rosario. Recuperado de https://n9.cl/damxp

Código Orgánico Integral Penal. (2018). Lexis Finder. Registro Oficial Suplemento 180 de 10-feb.-2014 Ultima modificación: 05-feb.-2018. Recuperado de https://n9.cl/xu3yi

Constitución del Ecuador. (2008). Artículo 54. Artículo 362. Registro Oficial 449 de 20oct-2008 Ultima modificación: 13-jul-2011. Recuperado de https://n9.cl/b1zqz

Couture, E. (2014). Los mandamientos del abogado [The commandments of the lawyer]. Recuperado de https://n9.cl/eh1lz

Domínguez, A. (2007). Derecho Sanitario y responsabilidad médica [Health Law and medical responsibility]. Valladolid: Lex Nova.

Donna, E. A. (2013). Derecho Penal, Parte General Tomo IV [Criminal Law, General Part Volume IV]. Buenos Aires: Rubinzal.Culzoni Editores. Recuperado de https://n9.cl/2vs3q

Guérez-Tricarico, P. (2012). El tratamiento Médico Curativo y su Licitud; El Papel del Consentimiento del Paciente [The Curative Medical treatment and its Lawfulness; The Role of Patient Consent]. Pamplona: Reuters Editores.

Jaimes, A. (2021). Algunas Reflexiones Sobre El Daño Antijurídico [Some Reflections on Unlawful Damage]. Recuperado de https://n9.cl/4pemr 
Ministerio de Salud Pública del Ecuador. (2016). Documento de socialización del Modelo de Gestión de Aplicación del Consentimiento Informado en la Práctica Asistencial. MSP [Document of socialization of the Management Model for the Application of Informed Consent in Care Practice. MSP]. Recuperado de https://n9.cl/invapli1

Muñoz, F. (2018). Teoría general del delito [General theory of crime] (5ta.). Recuperado de https://n9.cl/etals

Muñoz, F., \& García, M. (2010). Derecho Penal. Parte General [Criminal law. General part]. (8va.). Valencia: Tirant lo blanch.

Organización de las Naciones Unidas. (1945). Carta de las Naciones Unidas [Charter of the United Nations]. Recuperado de https://www.un.org/es/about-us/uncharter

Organización Mundial de la Salud. (2021). ¿Cómo define la OMS la salud? Recuperado 8 de noviembre de 2021, de Preguntas frecuentes website: https://n9.cl/ulotk

Torres-Proaño, I., \& Salazar-Sánchez, C. (2016). Vicios del consentimiento [Vices of consent]. Recuperado de https://n9.cl/6glxv

Rodríguez, J. (2020). La Corte Interamericana de Derechos Humanos y las Garantías Penales, Doctrina y jurisprudencia de la Corte IDH [The Inter-American Court of Human Rights and the Criminal Guarantees, Doctrine and jurisprudence of the Inter-American Court]. (Ulpiano, Ed.). Bolivia.

Roxin, C. (2019). La imputación objetiva en el Derecho Penal [The objective imputation in Criminal Law]. Lima: Ad-Hoc.

Terragni, M. A. (2003). El Delito Culposo en la Proxis Médica [Wrongful Crime in Medical Practice]: Buenos Aires. R. Culzoni.

Terragni, M. A. (2012). Tratado de Derecho Penal [Criminal Law Treaty]. Buenos Aires: La Ley S.A.

Zaffaroni, E., Alagia, A., \& Slokar, A. (2006). Manual de Derecho Penal Parte General [Criminal Law Manual General Part]. Buenos Aires: EDIAR. Recuperado de https://n9.cl/29stf 
Iustitia Socialis. Revista Arbitrada de Ciencias Jurídicas

Año VI. Vol. VI. N 1 . Edición Especial. 2021

Hecho el depósito de Ley: FA2016000064

ISSN: $2542-3371$

FUNDACIÓN KOINONIA (F.K). Santa Ana de Coro, Venezuela

Jaime Arturo Moreno-Martínez; María Auxiliadora Santacruz-Vélez; María Paola Aguilar-Rodas; Juan Carlos Álvarez-Pacheco

C2021 por los autores. Este artículo es de acceso abierto y distribuido según los términos y condiciones de la licencia Creative Commons Atribución-NoComercial-Compartirlgual 4.0 Internacional (CC BY-NC-SA 4.0)

(https://creativecommons.org/licenses/by-nc-sa/4.0/). 